\title{
Endothelial-Specific Molecule 1 (Endocan) as a Marker of Vascular Endothelial Regulation of Obesity-Associated Peripheral Polyneuropathy in the Non-Diabetic Obese Patients
}

\author{
NEARMEEN M. RASHAD, M.D.*; MONA M. AMER, M.D.**; RADWA M. AL-SAYED, M.D.***; \\ AZZA H. ABD EL-FATAH, M.D.* and HALA A. FATHY, M.D.** \\ The Departments of Internal Medicine*, Neurology** and Physiology***, Faculty of Medicine, Zagazig University, Egypt
}

\begin{abstract}
Background: The increasing incidence of obesity and its co-morbid situations poses a great challenge to worldwide health. Obesity has numerous co-morbidities including airway illness, insulin resistance, type 2 diabetes, atherosclerosis, peripheral polyneuropathy (PN) and cancer. Endocan is a proteoglycan that could be used as a biomarker of endothelial dysfunction.
\end{abstract}

Aim of Study: The current study aimed to investigate plasma endocan level in non-diabetic obese patients and to explore the association between circulatory endocan with the clinical and electrophysiological tests of PN in obese patients.

Methods: This cross-sectional controlled study enrolled 170 obese patients and 100 control group. The obese group was sub-classified according to BMI (Body Mass Index) into three groups; all participants were subjected to a complete neurological examination. The motor nerve conduction study of [median nerve, ulnar nerve, and Common Peroneal Nerve $(\mathrm{CPN})]$ and the sensory nerve conduction study of [median, ulnar and sural nerves] of all subjects were estimated. Blood sampling and biochemical analysis for parameters of metabolic syndrome (MetS) were done, in addition, Doppler evaluation of Carotid Intima Media Thickness (CIMT) using 0.9mm thickness as a cut-off point was used for identification of atherosclerosis. We measured plasma endocan by EnzymeLinked Immunosorbent Assay (ELISA).

Results: Obese patients with PN had statistically significant higher levels of plasma endocan $(218.6 \pm 26.26)$ compared to obese patients without PN (135.5 \pm 21.6$)$ and controls (13.1 \pm 3.2). Plasma endocan level was positively correlated with Toronto Clinical Scoring System (TCSS) and negatively correlated with measures of electrophysiological tests; Motor Nerve Conduction Velocities (MNCV) of median, ulnar nerves, Sensory Nerve Conduction Velocities (SNCV) of median and ulnar nerves, Compound Muscle Action Potential (CMAP) amplitude of median and ulnar nerves and Sensory Nerve Action Potential (SNAP) amplitude of median, ulnar and sural nerves. The identification of optimum cut-off point of serum

Correspondence to: Dr. Nearmeen M. Rashad,

E-Mail: nrashad78@yahoo.com.

n.rashad@zu.edu.eg.com endocan could help in evaluating non-diabetic obese patients with PN in attempt to decrease health hazards related to neuropathy.

Conclusion: Obese patients with PN had higher values of circulating endocan than obese patients without PN; the diagnostic power of circulating endocan was highly significant thus it could be used as a diagnostic biomarker of PN.

Key Words: Polyneuropathy - Nerve conduction studies Endocan-Obesity.

\section{Introduction}

THE occurrence of obesity is rapidly growing worldwide, the WHO currently estimates of obesity as a global health crisis are that 1.5 billion adults are overweight and 500 million adults are obese, the majority were found in developing countries [1]. It is linked with several comorbidities including Type 2 Diabetes Mellitus (T2DM), dyslipidemia, hypertension, coronary heart disease, osteoarthritis, sleep apnea, and respiratory problems, Peripheral Neuropathy (PN) as well as some types of cancers [2-4].

Adipose tissue has been recognized as a metabolically active endocrine tissue that affects energy and feeding regulation, glucose and lipid metabolism, neuroendocrine function, thermogenesis, reproduction, immunity and most relevantly cardiovascular function [5] . Chronic inflammatory condition in obesity causes dysregulation of the paracrine and endocrine activities of adipocyte-derived factors, which interrupt vascular homeostasis and contribute to vasodilator dysfunction of endothelium and subsequent microvascular dysfunction. The mechanistic link between these macrophage gene networks, obesity, and PN is not clear. Inter- 
estingly; insulin resistance and long-lasting inflammation are the mainstays of this disease [6].

Endothelial Dysfunction (ED) is an essential and very early step in atherogenesis and is expected to play a central role in the progress of vascular diseases [7]. ED can be defined as the total or partial loss of balance between vasodilators and vasoconstrictors, growth-inhibiting and promoting factors, anti-atherogenic and pro-atherogenic factors, and pro-coagulant and anti-coagulant factors [8]. ED is now considered as an early fundamental event in atherogenesis [9] and has been shown to precede the development of detectable atherosclerotic plaques in the coronary arteries [10], and considered an important factor in the progress of diabetic microvascular complications [11]

Endocan, recognized as an Endothelial Cellspecific Molecule (ESM), is a dermatan sulfate proteoglycan [12]. It is secreted particularly in lung, renal and tumor endothelium. ESM has also been estimated as a biomarker of endothelial dysfunction. Plasma level is elevated in lung injury, Chronic Kidney Disease (CKD), sepsis and Diabetic Proliferative Retinopathy (DPR) [13] . Its secretion is controlled by other cytokines such as TNF a [14]

This study was designed to explore the endocan plasma level in obese non-diabetic patients and to explore the connection between circulatory endocan with the clinical and electrophysiological tests of $\mathrm{PN}$ in obese patients.

\section{Subjects and Methods}

Subjects:

This cross-sectional controlled study was performed in the Outpatient Clinic of Neurology Department at Zagazig University Hospital from January 2017 to April 2018. This study involved 270 subjects. One hundred seventy obese patients' BMI > 30 achieved from Diabetes and Endocrinology Outpatient Clinic of Internal Medicine Department of Zagazig University.

Hospitals and 100 lean controls (BMI <25), which were matched to cases by age, sex, and ethnic origin.

The obese enrolled participants were then categorized according to their BMI into one of three subgroups: Group I [BMI $\left.=30-34.9 \mathrm{~kg} / \mathrm{m}^{2}\right]$; Group II $\left[\mathrm{BMI}=35-39.9 \mathrm{~kg} / \mathrm{m}^{2}\right]$ and Group III [BMI $>40$ $\mathrm{kg} / \mathrm{m}^{2}$ ]. All subjects were subjected to history taking, full clinical evaluation and neurological examination. The expert panel of the San Antonio conference recommends that diagnosis of PN should be based on neuropathic symptoms, and signs, and Nerve Conduction Studies (NCS) [15].

Full neurological examination was done. Anthropometric measures including Body Mass Index (BMI) calculated as weight in $\mathrm{kg} / \mathrm{height}$ in $\left(\mathrm{m}^{2}\right)$, waist circumference $(\mathrm{cm})$, hip circumference $(\mathrm{cm})$ to calculate Waist/Hip Ratio (WHR), Fat Mass Index (FMI\%) and Fat Free Mass Index (FFMI\%) were measured by Dual-Energy X-ray Absorptiometry (DEXA). Bodyweight had to be constant for at least 3 months before study. All subjects were on a free diet and were informed not to change their usual eating patterns. Exclusion criteria included current psychiatric disturbance that might interrupt the reliability of their response to the study questionnaire, hypertension, diabetes mellitus, thyroid, kidney, or liver diseases. Persons were also excluded if they took treatments known to affect metabolism, endocrine systems, or inflammation at the start of this study and during the preceding 6 months. Subjects with any neuropathic pain of non-diabetic origin including neck pain (radiculopathy) or lower back, post herpetic neuralgia, multiple sclerosis pain, cancer-related pain, spinal cord injury pain, phantom pain, carpal tunnel syndrome pain, or trigeminal neuralgia were excluded from the study. Also, we excluded pregnant patients. The Ethical Committee of the Faculty of Medicine, Zagazig University permitted our study protocol, and all members assigned written informed consent.

\section{Severity of neuropathy:}

The severity of neuropathy was sorted according to TCSS: For no neuropathy (1-5 points); for mild neuropathy (6-8 points); for moderate neuropathy (9-11 points); and for severe neuropathy (12-19 points). Symptoms, reflexes, and sensory tests, including pinprick, light touch, temperature, position, and vibration sense were done as part of the TCSS [16].

\section{Nerve Conduction Study (NCS):}

The median, ulnar, and CPNs motor NCS and the median, ulnar, and sural nerves sensory NCS of all subjects were measured by [Dantec Key point Workstation (Suite, CA, USA)]. According to Dyck et al. in 2011 revised criteria, abnormal Nerve Conduction Studies (NCS) were defined as one of the following criteria: Prolonged latency; reduction of conduction velocity; amplitude of Compound Muscle Action Potential (CMAP) and Sensory Nerve Action Potential (SNAP) [17] 
Blood sampling and biochemical analysis for parameters of MetS:

After an overnight fast blood samples were taken from all subjects for Fasting Plasma Glucose (FPG). We used the glucose oxidase method (Spinreact, Girona, Spain). Total Cholesterol (TC), High Density Lipoprotein (HDL) cholesterol, and Triglyceride (TG) levels were estimated by enzymatic methods (Spinreact, Girona, Spain). The Low Density Lipoprotein (LDL) cholesterol level was calculated using the Friedewald formula [TC] $[(\mathrm{HDL})+(\mathrm{TG} / 5)][18]$.

The concentrations Fasting Serum Insulin (FSI) were measured using a high-sensitivity ELISA kit provided by (Biosource Europe S.A., Nivelles, Belgium). Homeostasis Model Assessments of Insulin Resistance (HOMA-IR) were estimated [fasting insulin ( $\mathrm{N} / \mathrm{r} \mathbf{L})$ X fasting glucose $(\mathrm{mg} / \mathrm{dl})$ / 405] and also, B-cell functions (HOMA-B) [360 $\mathrm{X}$ insulin $(\mathrm{U} / \mathrm{mL})$ / (glucose $(\mathrm{mg} / \mathrm{dl})-36)]$ were calculated. Boster Endocan (ECSM1) human ELISA kit (Boster Biological Technology, Pleasanton CA, USA) was used to measure plasma endocan.

\section{Carotid Intima-Media Thickness (CIMT) meas- urement:}

Scanning of carotid arteries in transverse sections were starting from the common carotid arteries origins passing carotid sinuses, external carotid arteries and internal carotid arteries, and then inspected for carotid lesions in longitudinal sectors at different angles. 9 imaging of ultrasound were performed by B-mode ultrasonography (Toshiba Xario 200) with a center frequency of 7.5 MHzusing a linear probe (PLT-704 SBT).

\section{Statistical analysis:}

SPSS 21.0 (SPSS Inc., Chicago, IL, USA) was used for statistical analyses. Summary data were presented as mean standard lead and median distribution analysis. The test Kolmogorov-Smirnov was used to assess the normalization of the distribution. The Mann-Whitney U-test was used for comparisons between groups. Also, data on normal distribution were expressed as mean \pm SD using $t$-test. Pearson correlation coefficient was used to evaluate the association between endocan with anthropometric measures as well as electrophysiological parameters in patients. The potential accuracy of endocan was assessed by Receiver Operating Characteristic (ROC) analysis; the Area Under the Curve (AUC), and the cutoff values for diagnosis of PN among diabetic patients. $p<0.05$ considered to be significant at with a $95 \%$ Confidence Interval (CI).

\section{Results}

Among studied subjects, in the obese group, $20.4 \%$ were male and $79.6 \%$ were female, their mean ages were $45.95 \pm 7.63$ year. In the control group, $25.7 \%$ were male and $74.3 \%$ were female, their mean ages were $46.98 \pm 7.98$ years. The obese and the control group were matched for age, sex, and smoking.

\section{Anthropometric and biochemical features of the studied groups: \\ Significantly higher values of systolic and diastolic blood pressure as well as lipid profile; TG, TC and LDL were found in obese patients when compared to control group furthermore, significantly higher values of anthropometric meas- ures including, BMI, waist circumference, waist/hip ratio, FMI\% and FFMI\% in addition to FPG, FSI, HOMA-IR, hs-CRP, CIMT and TCSS were found in obese patients when compared to control group $(p<0.001)$. On the other hand, obese patients had lower significant values of HDL and HOMA-B when compared to the control group (Table 1).}

\section{General characteristics of obese patients:}

Obese without PN patients, there were statistically significant higher values of systolic blood pressure, BMI, FMI\%, FFMI\%, FSI, HOMA-IR and FPG in group III compared to group I. In addition, statistically significant higher values of BMI, waist circumference and waist/hip ratio were found in group II when compared to group I. On the contrary, both group II and group III had low significant values of HOMA-B compared to group I (Table 2).

Regarding obese patients with PN, there were statistically significant higher age, BMI, waist circumference, waist/hip ratio, FMI\%, FFMI\%, FPG, FSI, HOMA-IR and TCSS values in group III when compared to group I. In addition, group II had statistically significant higher BMI, waist circumference, FMI\%, and FFMI\% values compared to group I. On the contrary, both group II and group III had significant low values of HOMAB compared to group I (Table 2).

Comparison of plasma levels of endocan $(\mathrm{ng} / \mathrm{L})$ in the studied groups:

The current results showed that obese patients with PN had high statistically significant values of plasma endocan levels (218.6 \pm 26.26$)$ compared to obese patients without PN $(135.5 \pm 21.6)$ and controls (13.1 \pm 3.2$)$ as shown in Fig. (1A). 
Table (1): Anthropometric and biochemical characteristics of the studied groups.

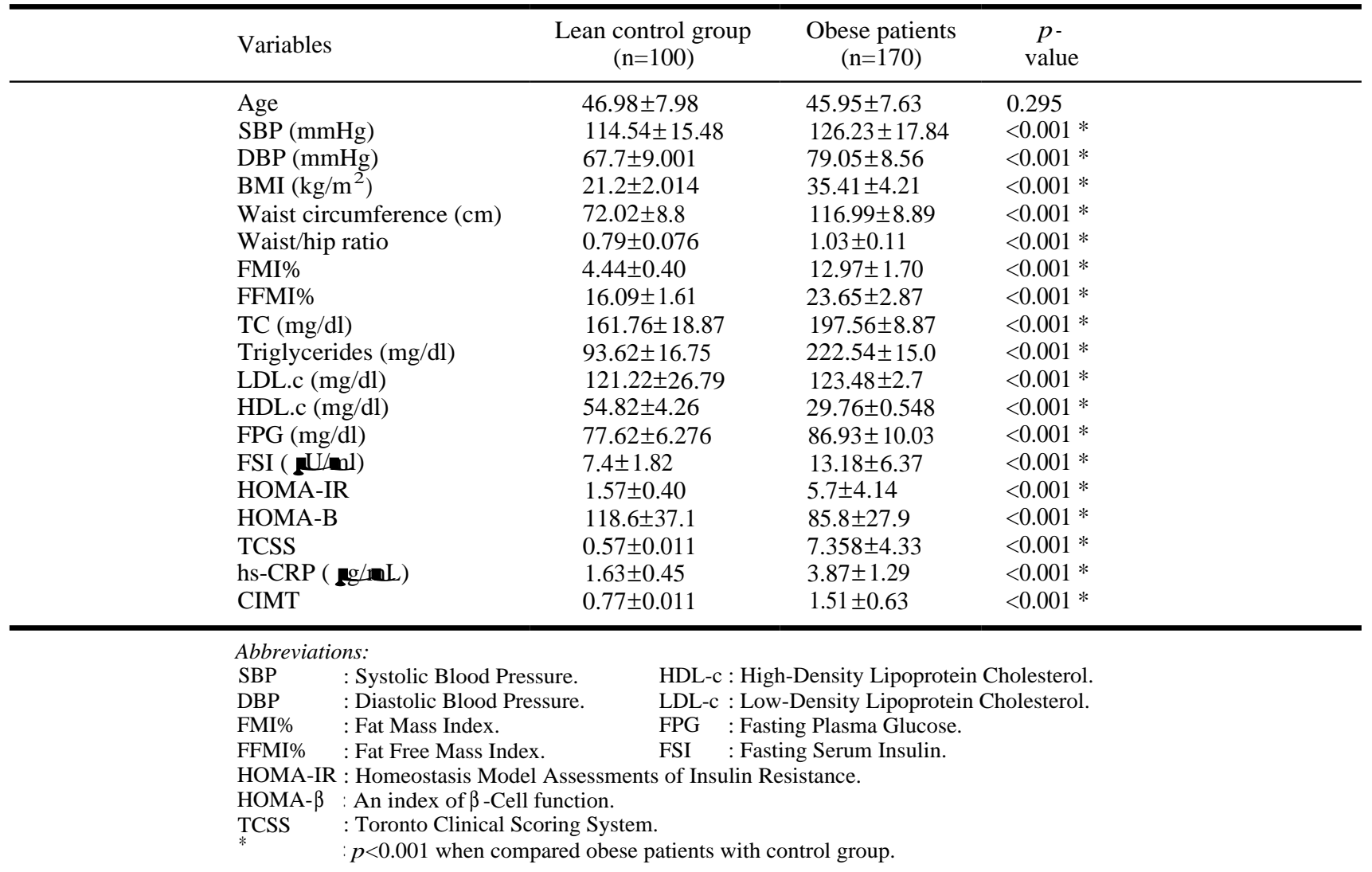

Table (2): Laboratory and anthropometric parameters of obese patients.

\begin{tabular}{|c|c|c|c|c|c|c|}
\hline \multirow{2}{*}{ Variable } & \multicolumn{3}{|c|}{$\begin{array}{l}\text { Obese without peripheral neuropathy } \\
\qquad(\mathrm{N}=65)\end{array}$} & \multicolumn{3}{|c|}{$\begin{array}{l}\text { Obese with peripheral neuropathy } \\
\qquad(\mathrm{N}=105)\end{array}$} \\
\hline & $\begin{array}{l}\text { Group I } \\
(\mathrm{n}=29)\end{array}$ & $\begin{array}{l}\text { Group II } \\
(\mathrm{n}=13)\end{array}$ & $\underset{(\mathrm{n}=23)}{\text { Group III }}$ & $\begin{array}{c}\text { Group I } \\
(\mathrm{n}=44)\end{array}$ & $\begin{array}{l}\text { Group II } \\
(\mathrm{n}=27)\end{array}$ & $\underset{(n=34)}{\text { Group III }}$ \\
\hline $\mathrm{SBP}(\mathrm{mmHg})$ & $122.1 \pm 11.7$ & $115.5 \pm 11.1$ & $131.5 \pm 24.1 \#$ & $128.8 \pm 19.7$ & $129.6 \pm 21.9$ & $127.2 \pm 18.9$ \\
\hline $\mathrm{DBP}(\mathrm{mmHg})$ & $73.7 \pm 9.82$ & $74.51 \pm 7.2$ & $80.05 \pm 8.9 \#$ & $79.0 \pm 7.57$ & $82.10 \pm 7.51$ & $81.41 \pm 7.5$ \\
\hline BMI $\left(\mathrm{kg} / \mathrm{m}^{2}\right)$ & $31.83 \pm 1.32$ & $37.2 \pm 1.6^{*}$ & $42.87 \pm 1.9 \#$ & $32.1 \pm 1.26$ & $37.13 \pm 1.2^{*}$ & $41.55 \pm 1.3 \#$ \\
\hline Waist circumference $(\mathrm{cm})$ & $112.1 \pm 6.3$ & $123.1 \pm 7.9^{*}$ & $116.3 \pm 9.67$ & $112.1 \pm 6.5$ & $120.8 \pm 6.5^{*}$ & $122.9 \pm 9.1 \#$ \\
\hline Waist/hip ratio & $0.99 \pm 0.094$ & $1.17 \pm 0.101^{*}$ & $1.02 \pm 0.118$ & $0.99 \pm 0.096$ & $1.03 \pm 0.087$ & $1.13 \pm 0.10 \#$ \\
\hline FMI\% & $10.8 \pm 1.40$ & $11.8 \pm 3.3$ & $12.49 \pm 1.6 \#$ & $10.9 \pm 0.52$ & $12.7 \pm 0.408 *$ & $14.1 \pm 0.528 \#$ \\
\hline FFMI $\%$ & $21.01 \pm 8.1$ & $26.71 \pm 6.57$ & $29.67 \pm 3.2 \#$ & $21.2 \pm 9.53$ & $24.6 \pm 0.79 *$ & $27.5 \pm 1.02 \#$ \\
\hline Total cholesterol (mg/dl) & $194.9 \pm 2.8$ & $197.3 \pm 3.26$ & $196.3 \pm 3.19$ & $198.4 \pm 2.6$ & $197.5 \pm 2.9$ & $197.2 \pm 3.1$ \\
\hline Triglycerides (mg/dl) & $222 . \pm 5.11$ & $224.1 \pm 6.32$ & $215.2 \pm 4.83$ & $224.2 \pm 4.8$ & $225.5 \pm 5.1$ & $224.1 \pm 5.2$ \\
\hline LDL.c (mg/dl) & $123.6 \pm 2.6$ & $123.1 \pm 2.9$ & $122.9 \pm 2.85$ & $124.0 \pm 14.5$ & $123.4 \pm 2.7$ & $123.1 \pm 2.9$ \\
\hline HDL.c (mg/dl) & $32.7 \pm 0.51$ & $31.8 \pm 0.6$ & $29.7 \pm 0.57$ & $29.6 \pm 5.51$ & $29.7 \pm 5.52$ & $29.8 \pm 0.72$ \\
\hline FPG (mg/dl) & $85.96 \pm 9.4$ & $88.49 \pm 8.08$ & $88.8 \pm 9.3$ & $80.3 \pm 08.6$ & $82.68 \pm 7.2$ & $90.1 \pm 8.5 \#$ \\
\hline FSI ( U/ml) & $6.8 \pm 1.40$ & $7.8 \pm 3.3$ & $10.49 \pm 1.6 \#$ & $8.9 \pm 0.52$ & $12.7 \pm 0.408^{*}$ & $14.1 \pm 0.528 \#$ \\
\hline HOMA-IR & $1.2 \pm 0.2$ & $1.7 \pm 0.6$ & $2.4 \pm 1.4 \#$ & $2.2 \pm 0.33$ & $3.2 \pm 1.5$ & $3.7 \pm 1.19 \#$ \\
\hline HOMA-B & $88.96 \pm 9.4$ & $88.49 \pm 8.08$ & $85.8 \pm 9.3$ & $90.3 \pm 8.6$ & $82.68 \pm 7.2$ & $80.1 \pm 8.5 \#$ \\
\hline TCSS & $3.35 \pm 2.95$ & $2.54 \pm 0.13$ & $2.91 \pm 2.43$ & $9.2 \pm 2.33$ & $9.48 \pm 2.1$ & $10.5 \pm 3.83 \#$ \\
\hline hs-CRP ( $\mathrm{g} / \mathrm{L} \mathrm{L})$ & $2.7 \pm 0.32$ & $3.05 \pm 0.89$ & $3.15 \pm 0.46 \#$ & $3.51 \pm 0.91$ & $4.97 \pm 1.1 *$ & $5.58 \pm 0.67$ \\
\hline CIMT & $0.99 \pm 0.094$ & $1.17 \pm 0.101 *$ & $1.02 \pm 0.118$ & $0.99 \pm 0.096$ & $1.03 \pm 0.087$ & $1.13 \pm 0.10 \#$ \\
\hline
\end{tabular}

Abbreviation:

SBP : Systolic Blood Pressure.

DBP : Diastolic Blood Pressure.

FMI\% : Fat Mass Index.

FFMI\% : Fat Free Mass Index.

HDL-c : High-Density Lipoprotein Cholesterol.

LDL-c : Low-Density Lipoprotein Cholesterol.

FPG : Fasting Plasma Glucose.

FSI : Fasting Serum Insulin.
HOMA-IR : Homeostasis Model Assessments of Insulin Resistance.

HOMA- $\beta$ : An index of $\beta$-cell function.

TCSS : Toronto Clinical Scoring System.

* $\quad: p<0.001$ when compared group II with group I.

\# $\quad: p<0.001$ when compared group III with group I. 


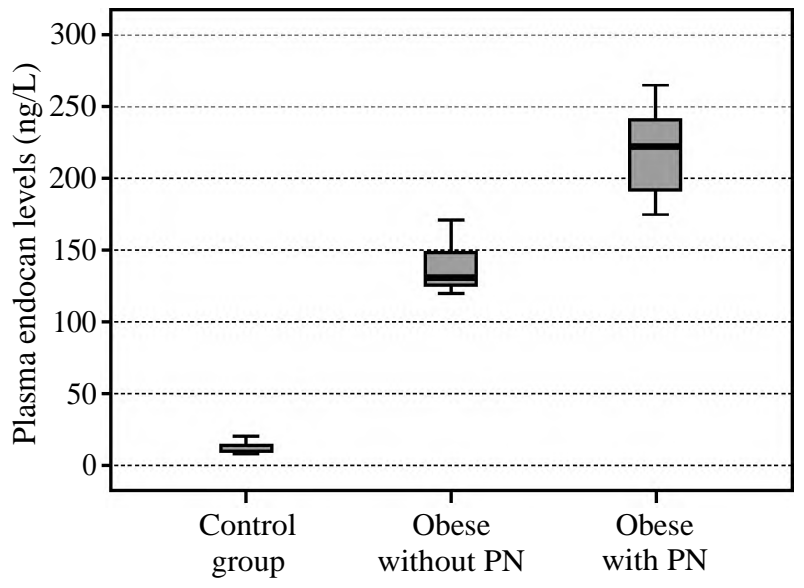

Fig. (1A): Comparison of plasma endocan level (ng/L) levels in studied groups.

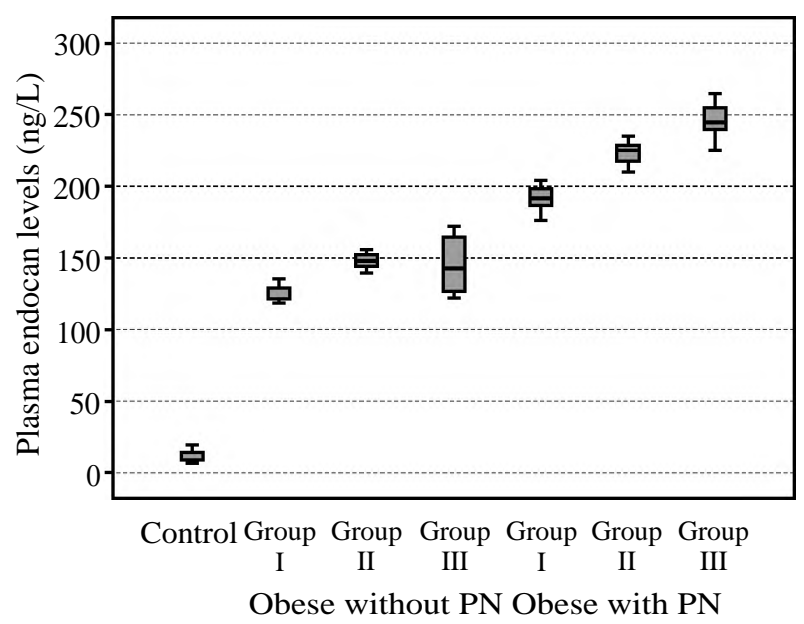

Fig. (1B): Comparison of plasma endocan level (ng/L) levels in studied groups.

Among obese patients, in obese patients without $\mathrm{PN}$, there were statistically significant higher values of plasma endocan levels in group III $(147.3 \pm 9.6)$ and group II (145.4 \pm 11.6$)$ compared to group I (123.5 \pm 13.6$)$. Regarding obese patients with PN, there were high statistically significant values of plasma endocan in group III (247.4 \pm 10.3$)$ and II (223.8 \pm 8.6$)$ compared to group I $(193.9 \pm 13.6)$ as shown in Fig. (1B).

\section{Electrophysiological tests of the studied groups:}

Nerve conduction velocities in the studied groups showed that Motor Nerve Conduction Velocities (MNCV) in median and PTN nerves were significantly reduced in obese with PN patients. Moreover, Sensory Nerve Conduction Velocities (SNCV) in the median and sural nerves were significantly decreased in obese patients with PN (Table 3).

Regarding amplitudes, CMAP amplitude in median and PTN were significantly diminished in obese patients with PN. SNAP amplitude in the median, sural nerves were significantly diminished in obese patients with PN compared to the control group while all other nerve amplitudes variances were not significant (Table 3 ).

Correlations between plasma endocan levels (ng/L) with TCSS as well as electrophysiological parameters in patients:

The current results demonstrated a significant positive correlation between plasma endocan levels (ng/L) with TCSS. On the contrary, there was a significant negative correlation with electrophysiological tests; MNCV (median and PT nerves), SNCV (median sural nerves), CMAP amplitude (median and PT nerves) and SNAP amplitude (median, and sural nerves) (Table 4).

Correlations between plasma endocan levels $(\mathrm{ng} / \mathrm{L})$ with parameters of MetS in obese patients:

The present results demonstrated significant positive correlations between plasma levels of endocan (ng/L) and parameters of MetS including diastolic blood pressure besides anthropometric measures; BMI, FMI\% and FFMI\% $(p<0.001)$ (Table 5).

Linear regression analyses in obese patients to evaluate the main independent parameters associated with plasma endocan levels ( $\mathrm{ng} / \mathrm{L})$ levels:

Linear regression analysis test displayed that plasma levels of endocan (ng/L) were correlated independently with BMI, waist circumference and WHR $(p<0.001)$ (Table 6).

Accuracy of plasma endocan levels ( $n g / L)$ for discriminating obese patients from control lean group by ROC analysis:

The potential diagnostic value of plasma endocan levels (ng/L) by ROC tests Fig. (2).

When obese patients discriminatedfrom the control group, the cutoff values were (18.2) and the AUC were 0.988 (95\% CI=0.978-0.999). Additionally, the sensitivities and the specificities were $97.1 \%$ and $99 \%$.

Accuracy of plasma endocan levels for discriminating $P N$ among obese patients by ROC analysis:

The potential diagnostic value plasma endocan levels by the ROC test Fig. (3). In obese patients, when patients with PN differentiated from patients without PN, the cutoff values of plasma endocan levels were (158.1) and the AUC was 0.983 (95\% $\mathrm{CI}=0.964-1.000$ ). Moreover, both of the sensitivities and the specificities were $96.6 \%$ and $92 \%$. 
Table (3): Comparison of clinical and electrophysiological tests of the studied groups.

\begin{tabular}{|c|c|c|c|c|c|}
\hline $\begin{array}{l}\text { Electrophysiological } \\
\text { parameters }\end{array}$ & $\begin{array}{c}\text { Control group } \\
(\mathrm{n}=50)\end{array}$ & $\begin{array}{c}\text { Obese patients } \\
\text { without PN, }(n=65)\end{array}$ & $\begin{array}{c}\text { Obese patients } \\
\text { with PN, }(n=105)\end{array}$ & $\begin{array}{c}p_{1-}^{-} \\
\text {value }\end{array}$ & $\begin{array}{l}p_{2-}^{-} \\
\text {value }\end{array}$ \\
\hline \multicolumn{6}{|l|}{$\operatorname{MNCV}(\mathrm{m} / \mathrm{s}):$} \\
\hline Median & $54.27 \pm 9.89$ & $53.48 \pm 11.35$ & $46.2 \pm 4.3$ & 0.441 & $<0.001 *$ \\
\hline PTN & $54.09 \pm 10.3$ & $55.01 \pm 11.27$ & $46.6 \pm 6.32$ & 0.345 & $<0.001 *$ \\
\hline $\mathrm{CPN}$ & $51.17 \pm 9.8$ & $51.95 \pm 11.62$ & $55.6 \pm 8.97$ & 0.531 & 0.051 \\
\hline \multicolumn{6}{|l|}{$\operatorname{SNCV}(\mathrm{m} / \mathrm{s}):$} \\
\hline Median & $52.29 \pm 9.79$ & $51.3 \pm 11.77$ & $43.36 \pm 4.65$ & 0.234 & $<0.001 *$ \\
\hline Ulnar & $52.20 \pm 9.83$ & $52.45 \pm 5.23$ & $52.04 \pm 8.26$ & 0.481 & 0.550 \\
\hline Sural & $52.03 \pm 9.87$ & $51.33 \pm 4.93$ & $50.78 \pm 5.56$ & 0.214 & 0.710 \\
\hline \multicolumn{6}{|l|}{ CMAP amplitude $(\mathrm{mV})$ : } \\
\hline Median & $7.92 \pm 0.48$ & $7.59 \pm 1.31$ & $4.6 \pm 0.5$ & 0.435 & $<0.001 *$ \\
\hline PTN & $8.14 \pm 1.48$ & $8.35 \pm 1.31$ & $5.6 \pm 0.5$ & 0.521 & $<0.001 *$ \\
\hline $\mathrm{CPN}$ & $6.65 \pm 1.48$ & $6.66 \pm 1.67$ & $5.89 \pm 1.39$ & 0.380 & 0.665 \\
\hline \multicolumn{6}{|l|}{ SNAP amplitude ( $\mathrm{V}) \mathbf{L}$} \\
\hline Median & $9.88 \pm 1.97$ & $9.14 \pm 1.87$ & $6.81 \pm 1.38$ & 0.312 & $<0.001 *$ \\
\hline Sural & $10.25 \pm 1.85$ & $10.61 \pm 2.34$ & $7.31 \pm 1.75$ & 0.513 & $<0.001 *$ \\
\hline Ulnar & $8.83 \pm 1.94$ & $8.44 \pm 1.68$ & $8.64 \pm 1.89$ & 0.184 & 0.507 \\
\hline
\end{tabular}

Table (4): Pearson correlation between plasma endocan with TCSS as well as electrophysiological parameters in obese patients.
Table (5): Pearson correlation coefficient between endocan level with anthropometric indices as well as parameters of metabolic syndrome among obese patients.

\begin{tabular}{|c|c|c|c|c|}
\hline \multirow{2}{*}{$\begin{array}{l}\text { Electrophysiological } \\
\text { parameters }\end{array}$} & \multicolumn{2}{|c|}{ Endocan } & \multirow{2}{*}{$\begin{array}{l}\text { Variables } \\
B M I:\end{array}$} & \multirow[t]{2}{*}{ Endocan } \\
\hline & $r$ & $p$ & & \\
\hline TCSS & 0.192 & $<0.05 *$ & $r$ & 0.527 \\
\hline$M N C V:$ & & & $p$ & $<0.001 *$ \\
\hline $\begin{array}{l}\text { Median } \\
\text { PTN }\end{array}$ & $\begin{array}{l}-0.258 \\
-0.263\end{array}$ & $\begin{array}{l}<0.01 * \\
<0.001 *\end{array}$ & FMI\%: & \\
\hline CPN & -0.063 & 0.412 & $r$ & 0.572 \\
\hline SNCV: & & & $p$ & $<0.001 *$ \\
\hline $\begin{array}{l}\text { Median } \\
\text { PTN }\end{array}$ & $\begin{array}{l}-0.268 \\
-0.264\end{array}$ & $\begin{array}{l}<0.001 * \\
<0.001 *\end{array}$ & FFMI\%: & \\
\hline Ulnar & -0.021 & 0.789 & $r$ & 0.568 \\
\hline Sural & -0.016 & 0.835 & $p$ & $<0.001 *$ \\
\hline $\begin{array}{l}\text { CMAP amplitude: } \\
\text { Median }\end{array}$ & -0.274 & $<0.001 *$ & $C I M T(\mathrm{~cm}):$ & \\
\hline PTN & -0.274 & $<0.001 *$ & $r$ & 0.267 \\
\hline $\mathrm{CPN}$ & -0.053 & 0.489 & $p$ & $<0.001 *$ \\
\hline SNAP amplitude: & & & $S B P(m m H g):$ & \\
\hline $\begin{array}{l}\text { Median } \\
\text { Sural }\end{array}$ & $\begin{array}{l}-0.194 \\
-0.194\end{array}$ & $<0.05 *$ & $r$ & 0.107 \\
\hline Ulnar & -0.059 & 0.444 & $p$ & 0.163 \\
\hline
\end{tabular}

Table (6): Linear regression analyses to test the influence of the main independent variables against plasma endocan circulatory levels (dependent variable) in obese patients.

\begin{tabular}{|c|c|c|c|c|c|c|c|}
\hline \multirow{2}{*}{ Model } & \multirow{2}{*}{$\begin{array}{l}\text { Unstandardized } \\
\text { Coefficients } \\
\text { B }\end{array}$} & \multirow{2}{*}{$\begin{array}{l}\text { Std. } \\
\text { Error }\end{array}$} & \multirow{2}{*}{$\begin{array}{l}\text { Standardized } \\
\text { Coefficients } \\
\text { Beta }\end{array}$} & \multirow{2}{*}{$t$} & \multirow{2}{*}{$\begin{array}{c}p- \\
\text { value }\end{array}$} & \multicolumn{2}{|c|}{ Endocan } \\
\hline & & & & & & Lower Bound & Upper Bound \\
\hline Endocan (constant) & 7.089 & 2.963 & & 2.393 & 0.018 & 12.940 & 1.239 \\
\hline DBP & 0.001 & 0.002 & 0.048 & 0.747 & 0.456 & 0.002 & 0.004 \\
\hline SBP & 0.001 & 0.001 & 0.104 & 1.659 & 0.099 & 0.000 & 0.003 \\
\hline BMI & 0.028 & 0.004 & 0.551 & 6.946 & $<0.001 *$ & 0.020 & 0.036 \\
\hline CIMT (cm) & 0.012 & 0.002 & 0.466 & 4.815 & $<0.001 *$ & 0.007 & 0.016 \\
\hline Waist/hip ratio & 0.817 & 0.190 & 0.422 & 4.299 & $<0.001 *$ & 1.192 & 0.442 \\
\hline $\mathrm{TC}$ & 0.008 & 0.006 & 0.102 & 1.335 & 0.184 & 0.004 & 0.019 \\
\hline TG & 0.008 & 0.005 & 0.189 & 1.593 & 0.113 & 0.002 & 0.018 \\
\hline FPG & 0.001 & 0.001 & 0.061 & 1.007 & 0.315 & 0.000 & 0.004 \\
\hline HDL & 0.083 & 0.051 & 0.211 & 1.634 & 0.104 & 0.017 & 0.184 \\
\hline
\end{tabular}




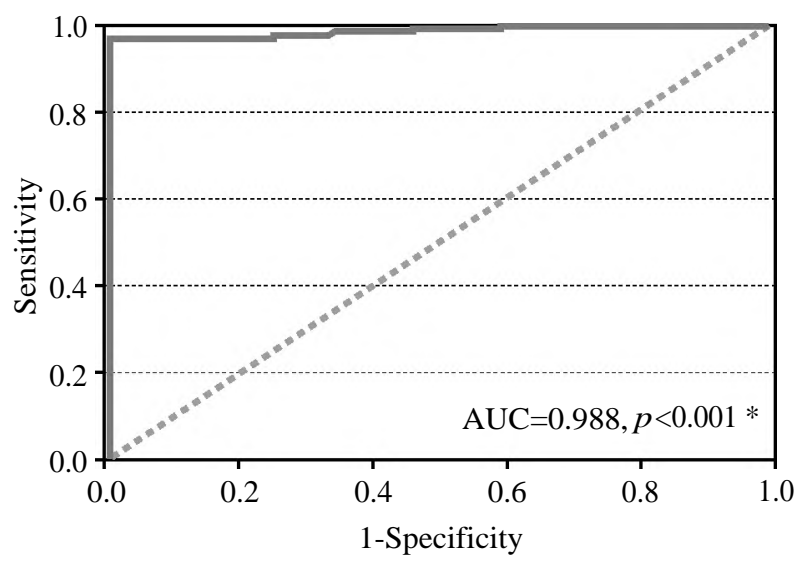

Fig. (2): ROC curve of plasma endocan for discriminating obese from lean subjects.

\section{Discussion}

Endothelial dysfunction is the earliest abnormality in the vascular disease development and is linked pathophysiologically to the progression of atherosclerosis and cardiovascular disease. Obesity is usually the result of the combination of an inappropriate lifestyle with genetic factors, and lack of regular physical activity. It is strictly related with the development of type 2 diabetes, dyslipidemia, hypertension, and cardiovascular disease, among other medical problems that are cumulatively harmful to the endothelium [19]

There is mounting evidence suggesting that obesity may cause slowing of nerve conduction. The pathophysiological role of obesity in PN could be due to mechanical and metabolic reasons including insulin resistance which is the most likely pathophysiology to clarify the incidence of median nerve injury among obese individuals [20]

Despite the growing evidence that the symptoms of PN are not a reliable indicator for the existence of neuropathy in the disease progression, as about $50 \%$ of patients with neuropathy are asymptomatic; therefore, they are liable to problems of insensate foot [21,22]. Thereby, early recognition of the highrisk population is enormously important. To address this need, we have focused on the estimation of the levels of plasma endocan level in obese non diabetic patients and to explore the association between circulatory endocan with the clinical and electrophysiological tests of $\mathrm{PN}$ in obese patients.

In this study, obese patients had high significant values of systolic and diastolic blood pressure as well as lipid profile; TG, TC, and LDL compared to the lean group. Even more importantly, obese patients had highsignificant values of TCSS compared to the control group.

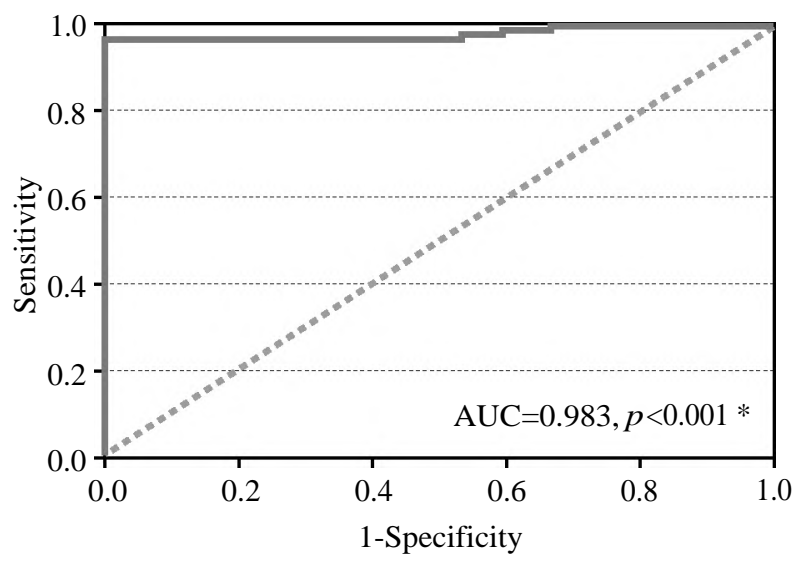

Fig. (3): ROC curve of plasma endocan for discriminating obese with PN from obese without PN.

Similar to the present findings, Aygul et al., reported that measurement of all NCSs parameters was significantly worse in obese as compared to lean patients [23].

According to this study, the incidence of PN was $62 \%$ among studied obese patients as we assessed our patients by both clinical scoring (TCSS) and electrophysiological tests.

According to Nenov et al., study the incidence of PN in grade II and III obesity with metabolic syndrome was $11 \%$ [24].

The present study observed that grade III obese with PN patients had high significant values of FPG, FSI and HOMA-IR compared grade I obese patients. Our findings are in concordance with the study of Miscio et al., they revealed subclinical peripheral nerve impairment in obesity due to metabolic alteration and insulin resistance which is significantly in obesity [25].

Supporting the results of that study, Yadav et al., found subclinical impairment of peripheral nerve in non-diabetic obese with abnormal NCS parameters. Prolonged periods but normal onset latencies and conduction velocities propose the involvement of slow conducting fibers. Also, reduced amplitudes might be due to the reduced number of stimulated fibers or/actual reduction in numerous axonal fibers or/defect at the neuromuscular junction in non-diabetic obese. These variations could be due to metabolic changes in obesity [26].

The results presented here are innovative; as a robust estimation of NCS in this study was performed in all subjects and detected that MNCV in median and PT nerves were significantly reduced in obese with PN patients compared to the control 
group. Also, SNCV in the median and sural nerves were significantly reduced in obese with $\mathrm{PN}$ patients. Regarding amplitudes, CMAP amplitude in median and PT nerves were decreased significantly in obese with PN patients compared to the control group. While, SNAP amplitude in median, and sural nerves were significantly reduced in obese with PN patients compared to the control group.

Related results were described in earlier studies of Werner et al. who showed that obese individuals have higher carpal tunnel pressure and sluggish conduction in the median nerve which supply the wrist [20].

Jagga et al., in 2011 studied the consequence of aging and anthropometric measures on the properties of nerve conduction and observed the negative correlation of nerve CV and BMI [27].

As regard amplitudes, our results showed CMAP amplitude in the median and PTN nerve was reduced significantly in both obese patients with or without PN compared to the control group. SNAP amplitude in the median, and sural nerves were reduced significantly in both obese patients with or without PN compared to the control group while all other differences of nerve amplitudes were not significant.

Findings of the present study were in concordance with Miscio et al., they found the amplitude of the median and tibial nerves were significantly lower in obese subjects as compared to the nonobese [25]. Also, the previous study observed that the presence of median mononeuropathy was significantly correlated to the increase of BMI $[28,29]$

The present study revealed obvious evidence that obese patients with PN had high statistically significant values of plasma endocan compared to obese patients without PN. Interestingly, in both obese groups; without or with PN, there were high statistically significant values of plasma endocan in group III and group II compared to group I.

Similarly, Bingol et al., conducted their study to evaluate the relationship between BMI and Obstructive Sleep Apnea (OSA)with endocan and they revealed that endocan is significantly higher in OSA and positively correlated with BMI [30]

Moreover, Yilmaz et al., study which conducted on the non-diabetic distinction in CKD patients, found a positive correlation between plasma endocan with proteinuria [31]

In contrast to the current study, Janke et al., observed that gene expression in subcutaneous adipose tissue of endocan was increased in obese, hyperinsulinemic women. In contrast, serum levels of ESM-1 were reduced in obese women and inversely correlated to the levels of C-reactive protein. These differences could be related to different gender as they study only on women however our study conducted on both sex [32]

According to our knowledge, no study conducted to evaluate PN in obese patients compared to obese without PN. In order to evaluate our results, we search for other study investigate endocan in correlation to microvascular diseases as they share the same pathophysiology and we found that Abu El-Asrar et al., observed higher plasma endocan levels in active Proliferative Diabetic Retinopathy (PDR) patients than inactive PDR and non-diabetic patients [33]

Moreover, Arman et al., observed that endocan in type 2 diabetics, had a positive correlation with urea albumin creatine ratio [34]

Against the current findings, Ali et al., detected that macroalbumin uricsubjects had low significant serum levels of endocan than normoalbuminuric subjects in our study. Furthermore, when UACR increased, we observed that serum endocan levels decreased [35]

To the best of our knowledge, this study is the first study had explored the correlation of plasma endocan with clinical scoring (TCSS) and electrophysiological tests. Noteworthy, our results confirmed that plasma endocan level had a significant positive correlation with TCSS and significant negative correlation with measures of electrophysiological tests; MNCV (median and PT nerves), SNCV (median and sural nerves), CMAP amplitude (median and PT nerves) and SNAP amplitude (median, and sural nerves).

Accordingly, the current data was analyzed by ROC to estimate the cutoff, AUC, sensitivity, and specificity of plasma endocan. Our results detected that the diagnostic power of plasma endocan levels was significantly high in differentiating obese patients from the control group as well as discriminating PN among obese patients.

In conclusion, the higher values of plasma endocan levels in obese non-diabetic patients especially patients with $\mathrm{PN}$ were positively correlated with TCSS and negatively correlated with measures of electrophysiological tests; MNCV (median and PTN nerves), SNCV (median and sural nerves), CMAP amplitude (median, and PTN nerves) and SNAP amplitude (median, and sural nerve). The 
identification of optimum cut-off point of plasma endocan level could help in evaluating obesity and $\mathrm{PN}$ in attempt to decrease health hazards related to neuropathy. Further future multicenter studies with a bigger sample size are needed to validate our findings.

\section{References}

1- World Health Organization. Obesity and Overweight. Available online: http://www.who.int/mediacentre/ factsheets/fs311/en/www.who.int/topics/obesity/en (accessed on 5 October 2017).

2- FRÜHBECK G.: Obesity: Screening for the evident in obesity. Nature Reviews Endocrinology, 8 (10): 570, 2012.

3- NG M., FLEMING T., ROBINSON M., THOMSON B., GRAETZ N., MARGONO C. and ABRAHAM J.P.: Global, regional, and national prevalence of overweight and obesity in children and adults during 1980-2013: A systematic analysis for the Global Burden of Disease Study 2013. The Lancet, 384 (9945): 766-81, 2014.

4- MOKDAD A.H., FORD E.S., BOWMAN B.A., DIETZ W.H., VINICOR F., BALES V.S. and MARKS J.S.: Prevalence of obesity, diabetes and obesity-related health risk factors, 2001. JAMA, 289 (1): 76-9, 2003.

5- WANG C.C.L., GOALSTONE M.L. and DRAZNIN B.: Molecular mechanisms of insulin resistance that impact cardiovascular biology. Diabetes, 53 (11): 2735-40, 2004.

6- YUDKIN J.S.: Adipose tissue, insulin action and vascular disease: Inflammatory signals. International Journal of Obesity, 27 (S3): S25, 2003.

7- MEYERS M.R. and GOKCE N.: Endothelial dysfunction in obesity: etiological role in atherosclerosis. Current Opinion in Endocrinology, Diabetes and Obesity, 14 (5): 365-9, 2007.

8- QUYYUMI A.A.: Endothelial function in health and disease: New insights into the genesis of cardiovascular disease. The American journal of medicine, 105 (1): 32S39S, 1998.

9- ROSS R.: Atherosclerosisan inflammatory disease N. Engl. J. Med., 340: 115-26. Find this article online, 1999.

10- MANO T., MASUYAMA T., YAMAMOTO K., NAITO J., KONDO H., NAGANO R. and KAMADA T.: Endothelial dysfunction in the early stage of atherosclerosis precedes appearance of intimal lesions assessable with intravascular ultrasound. American Heart Journal, 131 (2): $231-8,1996$.

11- TOOKE J.E.: Microvascular function in human diabetes: a physiological perspective. Diabetes, 44 (7): 721-6, 1995.

12- LASSALLE P., MOLET S., JANIN A., VAN DER HEYDEN J., TAVERNIER J., FIERS W. and TONNEL A.B.: ESM-1 is a novel human endothelial cell-specific molecule expressed in lung and regulated by cytokines. Journal of Biological Chemistry, 271 (34): 20458-64, 1996.

13- SCHERPEREEL A., DEPONTIEU F., GRIGORIU B., CAVESTRI B., TSICOPOULOS A., GENTINA T. and LASSALLE P.: Endocan, a new endothelial marker in human sepsis. Critical Care Medicine, 34 (2): 532-7, 2006.
14- SARRAZIN S., ADAM E., LYON M., DEPONTIEU F., MOTTE V., LANDOLFI C. and DELEHEDDE M.: Endocan or endothelial cell specific molecule-1 (ESM-1): A potential novel endothelial cell marker and a new target for cancer therapy. Biochimica et Biophysica Acta (BBA)Reviews on Cancer, 1765 (1): 25-37, 2006.

15- MEIJER J.W.G., BOSMA E., LEFRANDT J.D., LINKS T.P., SMIT A.J., STEWART R.E. and HOOGENBERG K.: Clinical diagnosis of diabetic polyneuropathy with the diabetic neuropathy symptom and diabetic neuropathy examination scores. Diabetes care, 26(3): 697-701, 2003.

16- SACHEDINA S. and TOTH C.: Association of comorbidities with increasing severity of peripheral neuropathy in diabetes mellitus. World Journal of Diabetes, 4 (4): 135, 2013.

17- DYCK P.J., CARTER R.E. and LITCHY W.J.: Modeling nerve conduction criteria for diagnosis of diabetic polyneuropathy. Muscle \& nerve, 44 (3): 340-5, 2011.

18- FRIEDEWALD W.T., LEVY R.I. and FREDRICKSON D.S.: Estimation of the concentration of low-density lipoprotein cholesterol in plasma, without use of the preparative ultracentrifuge. Clinical chemistry, 18 (6): 499-502, 1972.

19- PI-SUNYER F.X.: The obesity epidemic: pathophysiology and consequences of obesity. Obesity research, 10 (S 12): 97S-104S, 2002.

20- WERNER R.A., JACOBSON J.A. and JAMADAR D.A.: Influence of body mass index on median nerve function, carpal canal pressure, and cross-sectional area of the median nerve. Muscle \& nerve, 30 (4): 481-5, 2004.

21- WU S.C., DRIVER V.R., WROBEL J.S. and ARMSTRONG D.G.: Foot ulcers in the diabetic patient, prevention and treatment. Vascular health and risk management, 3 (1): 65, 2007.

22- BOULTON A.J., VINIK A.I., AREZZO J.C., BRIL V., FELDMAN E.L., FREEMAN R. and ZIEGLER D.: Diabetic neuropathies: A statement by the American Diabetes Association. Diabetes care, 28 (4): 956-62, 2005.

23- AYGÜL R., ULVI H., KOTAN D., KUYUCU M. and DEMIR R.: Sensitivities of conventional and new electrophysiological techniques in carpal tunnel syndrome and their relationship to body mass index. Journal of brachial plexus and peripheral nerve injury, 4 (1): 12, 2009.

24- NIENOV O.H., MATTE L., DIAS L.S. and SCHMID H.: Peripheral polyneuropathy in severely obese patients with metabolic syndrome but without diabetes: Association with low HDL-cholesterol. Revista da Associação Médica Brasileira, 63 (4): 324-31, 2017.

25- MISCIO G., GUASTAMACCHIA G., BRUNANI A., PRIANO L., BAUDO S. and MAURO A.: Obesity and peripheral neuropathy risk: A dangerous liaison. Journal of the peripheral nervous system, 10 (4): 354-8, 2005.

26- YADAV R.L., SHARMA D., YADAV P.K., SHAH D.K., AGRAWAL K., KHADKA R. and ISLAM M.N.: Somatic neural alterations in non-diabetic obesity: A cross-sectional study. BMC Obesity, 3 (1): 50, 2016.

27- JAGGA M., LEHRI A. and VERMA S.K.: Effect of aging and anthropometric measurements on nerve conduction 
properties-A review. Journal of exercise science and physiotherapy, 7 (1): 1, 2011.

28- KOUYOUMDJIAN J.A., ZANETTA D.M. and MORITA M.P.: Evaluation of age, body mass index, and wrist index as risk factors for carpal tunnel syndrome severity. Muscle \& Nerve: Official Journal of the American Association of Electrodiagnostic Medicine, 25 (1): 93-7, 2002.

29- HSIEH L.P. and CHIANG D.H.: The relationship between obesity and the diagnosis of carpal tunnel syndrome. J. Cheng. Ching Med., 1: 39-43, 2005.

30- BINGOL Z., KOSE M., P1HT1L1 A., AKP1NAR T., TUKEK T. and K1YAN E.: Serum endothelial cell specific molecule-1 (endocan) levels in patients with obstructive sleep apnea. Biomarkers in medicine, 10 (2): 177-84, 2016.

31- YILMAZ M.I., SIRIOPOL D., SAGLAM M., KURT Y.G., UNAL H.U., EYILETEN T. and VURAL A.: Plasma endocan levels associate with inflammation, vascular abnormalities, cardiovascular events, and survival in chronic kidney disease. Kidney international, 86 (6): 1213-20, 2014.
32- JANKE J., ENGELI S., GORZELNIAK K., FELDPAUSCH M., HEINTZE U., BÖHNKE J. and SHARMA A.M.: Adipose tissue and circulating endothelial cell specific molecule- 1 in human obesity. Hormone and Metabolic Research, 38 (01): 28-33, 2006.

33- ABU EL-ASRAR A.M., NAWAZ M.I., De HERTOGH G., AL-KHARASHI A.S., VAN DEN EYNDE K., MOHAMMAD G. and GEBOES K.: The angiogenic biomarker endocan is upregulated in proliferative diabetic retinopathy and correlates with vascular endothelial growth factor. Current eye research, 40 (3): 321-31, 2015.

34- ARMAN Y., AKPINAR T.S., KOSE M., EMET S., YURUYEN G., AKARSU M. and AYDIN S.: Effect of glycemic regulation on endocan levels in patients with diabetes: A preliminary study. Angiology, 67 (3): 239-44, 2016.

35- MEHMET ALI CIKRIKCIOGLU, ZEYNEP ERTURK, ELIF KILIC, KENAN CELIK, ISKENDER EKINCI, AYSE IREM YASIN CETIN, et al.: Endocan and albuminuria in type 2 diabetes mellitus. Renal Failure, 38: 10,1647-1653, Doi: 10.1080/0886022X.2016.1229966, 2016.

\section{الآندوكان كعلامة لتنظيم البطانة الوعائية للإعتلال العصبى المرتبط بالسمنة

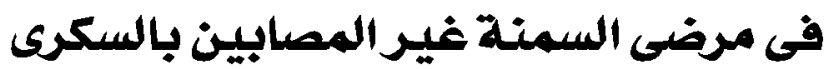

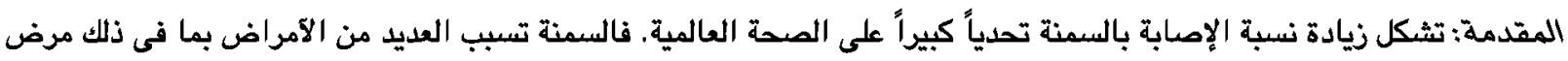

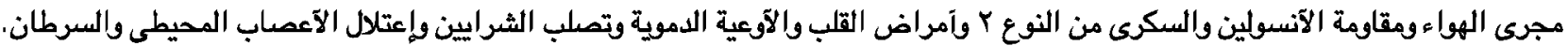

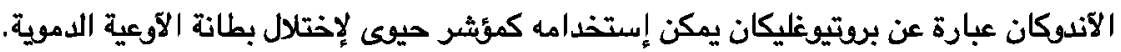

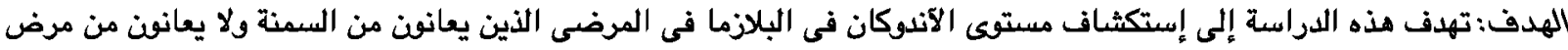

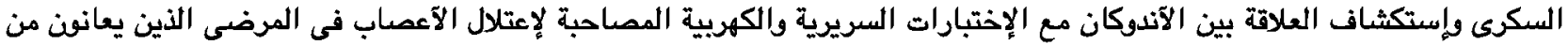

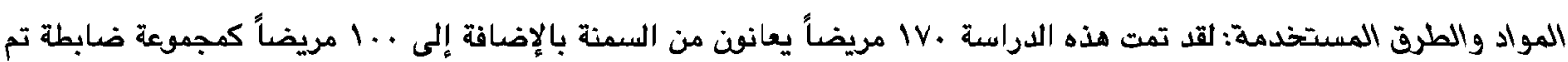

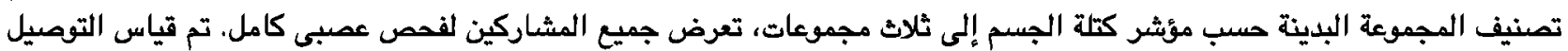

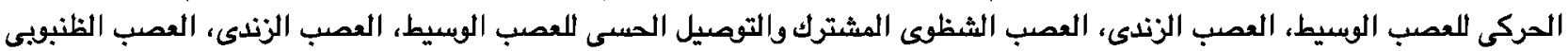

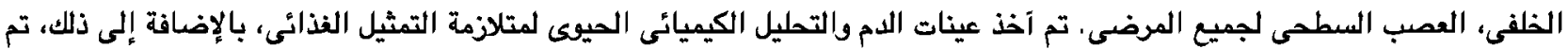
عمل لوبلر السمك الوسائط الداخلية السباتية بإستخدام سمك 9. ..مم كنقطة فاصلة التشخيص تصلب الشرايين. وآيضاً قمنا بقياس الآندوكان في البلازما.

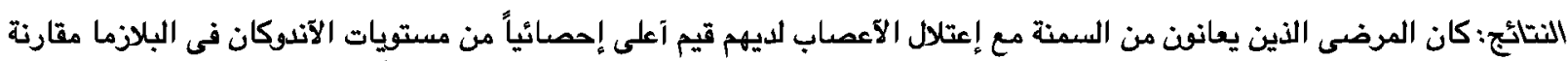

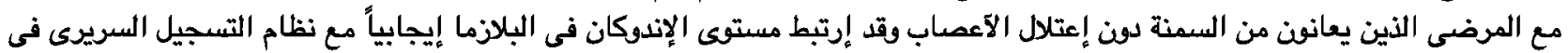

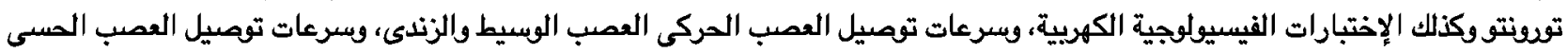

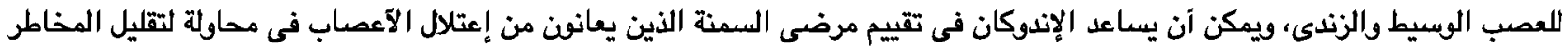
الصحية المتعلقة بالإعتلال العصبى، الصني.

الخلاصة: إن المرضى الذين يعانون من السمنة مع إعتلال الآعصاب لوحظ آن لديهم قيم آعلى من الإندوكان من المرضى يعانئ يعانون من

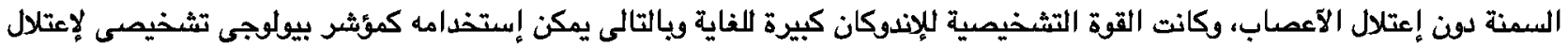

